\title{
Design and Analysis of Microstrip Antenna for CDMA Systems Communication
}

\author{
Eng: Hassan Elesawy ${ }^{1}$, Dr: W. Swelam ${ }^{2}$, Dr: Abdal.Fouda ${ }^{3}$, Prof. Dr. I. Hafez ${ }^{4}$ \\ 1(Electronics and Communication, Faculty of Engineering, Ain Shams University, Cairo, Egypt) \\ 2(Electronics and Communication, Faculty of Engineering, Ain Shams University, Cairo-Egypt) \\ 3 (Communication, Faculty of Engineering, Modern Academy; \\ 4 (Chairman of Electronics and Communication, Faculty of Engineering, Ain Shams University, Cairo-Egypt)
}

\begin{abstract}
This paper proposes a newly designed microstrip patch antennas (MSA) for wireless application (CDMA Systems). The designed single antenna E-shaped patch antenna. Two parallel slots are in corporated into the patch of a microstrip antenna to expand it bandwidth, and designed antenna operates in the frequency range of 1.85 to $1.99 \mathrm{GHz}$. The antenna is designed using air as a dielectric substrate between the ground plane and substrate patch antenna. IE3D is a full-wave electromagnetic simulator based on the method of moments $(M o M)$ technique. It has been widely used in the design of MICs, RFICs, patch antennas, wire antennas, and other RF/wireless antennas. It can be used to calculate and plot the S parameters, VSWR, current distributions as well as the radiation patterns. The results obtained for each patch were $2 D$ and $3 D$ view of patch, Directivity, Gain, beam width and other such parameters, true and mapped $3 D$ radiation pattern, and $2 D$ polar radiation pattern. The antenna successfully achieves the exhibit a broad impedance bandwidth of $27 \%$ (at VSWR <2) with respect to the center frequency of $1.9 \mathrm{GHz}$ is designed, fabricated, and finally measured on Spectrum analyzer. The radiation pattern and directivity are also presented.. Gain maximum achievable is $3 \mathrm{dBi}$ and good return loss (S11 parameters) of $-30 \mathrm{~dB}$ is achieved along with broadside radiation pattern.
\end{abstract}

Keywords - Microstrip Patch Antenna; E-shaped, CDMA systems communications; Coaxial Probe feed, IE3D.

\section{Introduction}

Due to the rapid progress in various wireless communication systems, more researches are required to develop antennas with reduced size and enhanced frequency bandwidth to meet the miniaturization requirements of mobile systems such as mobile cellular, mobile cordless. Each wireless communication standard will require an antenna that resonates at its frequency of operation. With multiple standards and services, one could easily imagine a multitude of antennas required both at the base station site, and also on the mobile device. One of types of wireless communication at $1.9 \mathrm{GHz}$ is Wireless fidelity CDMA systems, personal communication system (PCS) and other next-generation wireless systems. One of the key components interfacing between the CDMA system hardware and the 'Ether', i.e. the air-interface for wireless communication is the antenna. With tremendous growth and demand for high speed high data rate wireless communication, more and more antennas, and antennas covering a multitude of frequency bands are required.

Antennas play a very important role in the field of wireless communications. Some of them are parabolic reflectors, patch antennas, slot antennas and folded dipole antennas. Each type of antenna is good in its own properties and usage. We can say antennas are the backbone and almost everything in the wireless communication without which the word could have not reached at this age of technology. It is well known that MSA are attractive and popular due to their natural advantages such as small size, low weight and low cost of production. Possible techniques for increasing its frequency bandwidth have received much attention. In addition to the common techniques of increasing patch height and decreasing substrate permittivity, a popular method which is the use of parasitic patches [1]. Patch antennas play a very significant role in today's world of wireless communication systems. Another way to increase the bandwidth of an MSA is to decrease the dielectric constant of the substrate [2]. This paper presents an E-shaped antenna for mobile base station using microstrip antenna (MSA) covered. The advantages of this proposed antenna are light weight, easy fabrication and installation, and moderately high gain compare to the other antennas in the cellular phone system at present. Moreover, it provides a Broadside-shaped radiation pattern and wider in the horizontal direction.

In this paper, we present a novel single-patch wide-band microstrip antenna: the E-shaped patch antenna. When two parallel slots are incorporated into the antenna patch, the E-shaped patch antenna is simpler in construction. By only adjusting the length, width, and position of the slots, one can obtain satisfactory performances. Some experimental results prove the validity of this design. The method of moments with the vector triangular basis function [3] is used for analysis, as well as IE3D software. The electric currents on the Eshaped patch are calculated and graphically presented to explain the wide-band mechanism. Subsequently, a wide-band E-shaped patch antenna with $27 \%$ bandwidth is designed to cover 1.85-1.99 GHz frequency. This 
range of frequency is very desirable in modern wireless communications. Radiation patterns are also measured and compared with the numerical data. However, this has detrimental effects on antenna size reduction since the resonant length of an MSA is shorter for higher substrate dielectric constant. In addition, the directivity of the MSA depends on the dielectric constant of the substrate. The next section describes the antenna design and the idea of operation. Section 3 covers the simulation process and results analysis. Section 4 shows the conclusion. Show the Reference is final section.

\section{Antenna Design}

The software part of our design antenna around determination of the surface current distribution and return loss curve (S11vs frequency) of several simple rectangular patch antennas. From the transmission line model of rectangular patch antennas it is clear that the three essential parameters for the design of a rectangular Microstrip Patch Antenna are as follows: Frequency of operation $\left(\mathrm{f}_{0}=1.9 \mathrm{GHz}\right)$. Dielectric constant of the substrate $\left(\varepsilon_{\mathrm{r}}=2.2\right)$ and height of dielectric substrate thickness $(\mathrm{h}=1.5748 \mathrm{~mm})$.

\section{Design Procedure [3]}

The geometry of proposed antenna is shown in Figure (1). The design consists of rectangular Microstrip Patch Antenna with etched E- shape on it. Calculating the wavelength $(\lambda)$, because the light speed $\mathrm{C}=3 \times 10^{8}$ and $f_{0}=1.9 \mathrm{GHz}$, So $\lambda=\mathrm{C} / f_{0}$, we get $\lambda=0.157 \mathrm{~m}=157 \mathrm{~mm}$. The E-shaped rectangular patch antenna was fabricated, simulated using Zealand IED3 simulator. The basic geometry of the E-shaped antenna element is shown in Fig.1. The rectangular patch, with width $\mathrm{W}$ and length $\mathrm{L}$ is supported by a low dielectric superstrate with dielectric permittivity $\epsilon_{1}$ and thickness $h_{1}$, an air-filled substrate with dielectric permittivity $\epsilon_{0}=1$ and thickness $h_{0}=15 \mathrm{~mm}$ is sandwiched between the superstrate and a ground plane. The proposed patch integrates the E-shaped patch that adjusting the length 1 , width $w 1$, and positions $d_{p}$ of the slots one can obtain satisfactory performance and control the bandwidth. By properly adjusting the parameters of slots and the position of the feeding point, a $27 \%$ antenna bandwidth is achieved. An elegant approach for the parameter selection would be the utilization of modern genetic algorithms [4]..

The computer simulation of the proposed linear array antenna was performed using MATLAB [5] and the calculated parameters are shown in Table1[4,5]. The calculations used are described below. Since the two basic factors influencing the performance of the linear array antenna, i.e., the inter-element spacing and the number of elements in an array are fixed in our analysis. We properly selected the size of the patches and the position of the feeding point. The initial dimensions L, W of the E-shaped patch antenna can be determined using the following equations, which are valid for the rectangular patch antenna $[4,5]$ :

The width of the Microstrip patch antenna is given as: $\quad w=c /\left(2 \mathrm{f}_{\circ} \sqrt{\left(\varepsilon_{\mathrm{r}}+1\right) / 2}\right)=62.4 \mathrm{~mm}$

The effective length is: $\quad \mathrm{L}_{\mathrm{eff}}=\mathrm{C} /\left(2 \mathrm{f} \circ \sqrt{\varepsilon_{\mathrm{reff}}}\right)=52.23 \mathrm{~mm}$;

The length extension is:

$\Delta \mathrm{L}=(0.412 \mathrm{~h})\left(\varepsilon_{\text {reff }}+0.3\right) *((\mathrm{~W} / \mathrm{h})+0.264) /\left(\varepsilon_{\text {reff }}-0.258\right) *((\mathrm{~W} / \mathrm{h})+0.8)$

The actual length is obtained by: $\quad \mathrm{L}=\mathrm{L}_{\mathrm{eff}}-2 \Delta \mathrm{L}=50.6 \mathrm{~mm}$

\section{Calculation of the ground plane dimensions ( $\mathrm{Lg}$ and Wg):}

The transmission line model is applicable to infinite ground planes only. However, for practical considerations, it is essential to have a finite ground plane. It has been shown by [6] that similar results for finite and infinite ground plane can be obtained if the size of the ground plane is greater than the patch dimensions by approximately six times the substrate thickness all around the periphery. Hence, for this design, the ground plane dimensions would be given as:

$L_{g}=6 h+L=6(1.5748)+50.6=59.6 \approx 60 \mathrm{~mm}$

$w_{g}=6 h+w=6(1.5748)+62.4=71.8 \approx 72 \mathrm{~mm}$

This design employs contemporary techniques namely, the coaxial probe feeding, patch, and slotted patch techniques to meet the design requirement. The use of probe feeding technique with a thick air-filled substrate provides the bandwidth enhancement, while the application of substrate with radiating patch offers a gain enhancement, and the use of parallel slots also reduce the size of the patch [3,7].

The proposed patch integrates with slot on the same radiating element are embedded in parallel on the radiating edge of the patch symmetrically with respect to the centerline of the patch. 
Table 1: Optimize Parameters for E-Shaped Patch Antenna.

\begin{tabular}{|l|l|}
\hline Superstrate & RT $5880\left(\varepsilon_{\mathrm{r}}=2.2, \mathrm{~h}=1.5748 \mathrm{~mm}\right)$ \\
\hline Substrate Air & Air $\left(\varepsilon_{0}=1, \mathrm{~h}_{0}=15 \mathrm{~mm}\right)$ \\
\hline Rectangular patch & Width and Length, $\{\mathrm{W}, \mathrm{L}\}=\{62.4,50.6\} \mathrm{mm}$ \\
\hline Feed Position & $\mathrm{dp}=2.8 \mathrm{~mm}$ from bottom edge along y axis (centre line of the patch), hole $=0.7 \mathrm{~mm}$ \\
\hline Slots parameters & $\left\{l, \mathrm{w}_{2}, \mathrm{w}_{1}\right\}=\{44.5,8,9\} \mathrm{mm}$ \\
\hline
\end{tabular}

An Aluminum plate with dimensions of $60 \times 72 \times 1 \mathrm{~mm}$ and thickness of $1 \mathrm{~mm}$ is used as a ground plane.

\section{Simulation Process And Results Analysis}

In this paper we have Simulation and Fabricated in systematic way and finally measured on Spectrum analyzer. The proposed antenna element is analyzed using the full-wave MoM technique with the aid of the zeland-IE3D full-wave electromagnetic simulator [8]. To calculate return loss, VSWR, impedance bandwidth, Current distribution, antenna efficiency and gains. Fig. (2) Shows the simulated return loss (S11) parameter is better than $-10 \mathrm{~dB}$ within the frequency range of (1.83-1.99) $\mathrm{GHz}$, which means $27 \%$ band-width enhancement.

Fig. (3) shows the simulated result of the VSWR of the proposed antenna. The minimum value of VSWR should be less than $2(\mathrm{VSWR} \leq 2)$ for desirable communication is about $1.83-2 \mathrm{GHz}$. The closely excited resonant frequencies at $1.9 \mathrm{GHz}$ as shown in the figure gives the measure of the characteristic of the patch antenna. Fig. (4) Shows the simulated gain of the proposed patch antenna at various frequencies is shown in the figure, the maximum achievable gain is $3 \mathrm{dBi}$ at the frequency of $1.9 \mathrm{GHz}$ and the gain variation is $1 \mathrm{dBi}$ between the frequency ranges of $1.85 \mathrm{GHz}$ to $1.99 \mathrm{GHz}$. Fig.(5) Shows the simulated Radiation Pattern Plot. Fig. (6) Shows that the surface current distribution, including the current flow on slotted area of the patch. Due to identical manner of current flow on the antenna, only current distribution on the resonant frequency is depicted in the figure. Arrows show the direction of the current distribution. It can be observed from the figure that the current intensely flows at the edge of the slots especially near the feeding probe of the patch. However, the current is uniformly distributed elsewhere. Fig.(7) Shows that the simulated radiation efficiency and antenna efficiency of the proposed antenna at $(1.83$ - 2) GHz. The radiation pattern efficiency displays good broadside radiation patterns is $65 \%$ at most of frequency band. The proposed patch antenna efficiency is $60 \%$ at most of frequency band.

\section{Conclusion}

A new E shaped patch for enhancing bandwidth of microstrip patch antenna is successfully designed in this paper. By employing proposed slotted patch shaped design and coaxial probe feeding techniques, an impedance bandwidth of $27 \%$ is achieved in this design with respect to the centre frequency of $1.9 \mathrm{GHz}$. In addition, good antenna gain and radiation characteristics have also been obtained. The proposed microstrip patch antenna achieves a fractional bandwidth of $27 \%(1.83$ - 2) $\mathrm{GHz}$ at $10 \mathrm{~dB}$ return loss covering the CDMA systems band. The maximum achievable gain of the antenna is $3 \mathrm{dBi}$ with gain variation of $1.3 \mathrm{dBi}$.

The developed element can be used in mobile communication systems (CDMA system (PCS)) with stable manner. The proposed element is designed and simulated using the method of moment (MoM) technique with the aid of the zeland-IE3D full-wave electromagnetic simulator. The radiation pattern shows the broad-side E-shape that is suitable for such systems with gain value that exceeds $3 \mathrm{dBi}$ at $1.9 \mathrm{GHz}$. Better radiation performance is achieved by embedding slot onto the patch (E-shaped) while the use of patch improves the gain of the antenna. The composite effect of integrating these techniques offers a low profile, broadband, high gain, and compact antenna element suitable for array applications.

\section{Reference:}

[1] G. Guru Prasad, G. Madhavi Latha, V. Charishma,"Design and Analysis of 8x1 Array Microstrip Patch Antenna Using IE3D" , International Journal of Engineering and Innovative Technology (IJEIT)Volume 1, Issue 3, March 2012.

[2] Sanchez-Hernandez, D., Robertson, I. D., “A Survey of Broadband Microstrip Patch Antennas”. Microwave Journal, Sept. 1996, pp. 60-82.

[3] F. Yang, X. Zhang, Y. Rahmat-Samii, "Wide-band E-shaped patch antennas for wireless communications," IEEE Trans. Antennas Propagation, vol. 49, pp. 1094-1100, july2001 .

[4] Godara Lal Chand."Handbook of Antennas in Wireless Communications", Boca Raton London New York CRC Press, 2002.

[5] J. Davalos Guzman, S. Gomez Ochoa, N. Ramirez Hernandez, J. L. Ramos Quirarte, "MATLAB Tool for Analysis and Design of Linear and Planar Antenna Arrays", 1 st International Congress on Instrumentation and Applied Sciences, Cancun Q.R. Mexico, October 26-29, 2010.

[6] C. A. Balanis, “Antenna Theory, Analysis and Design,” John Wiley \& Sons, New York, 2005.

[7] M. Tariqul Islam, M.N. Shakib, N. Misran., and B. Yatim, " Analysis of L-Probe Fed Slotted Microstrip Patch Antenna," in Eleventh IEEE International Conference on Communicat-ion Systems (IEEE ICCS 2008), Guangzhou, China, pp. 380-383, November 19-21, 2008 .

[8] Milligan, T.A.,"Modern Antenna Design", John Wiley \& Sons Publication, New Jersey, 2005.http://www.zeland.com 


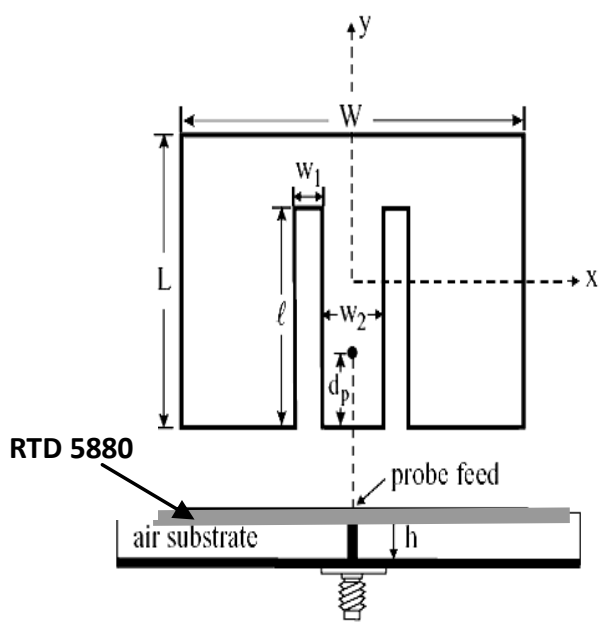

Fig.1: Geometry of E-shaped MSA, (a) Top view

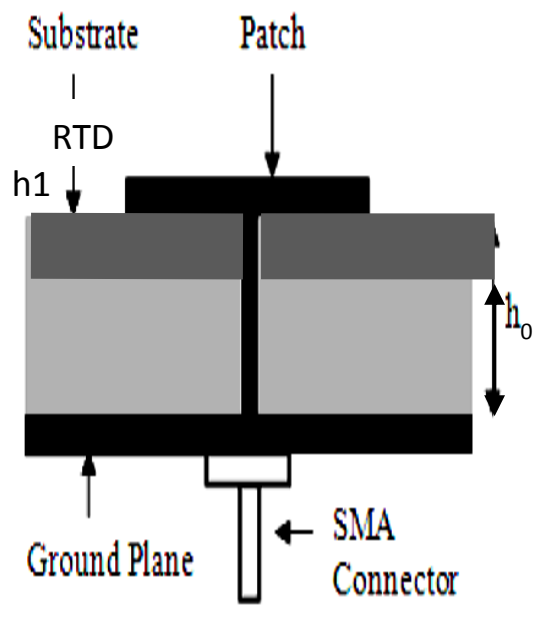

Fig.1. (b) Side view

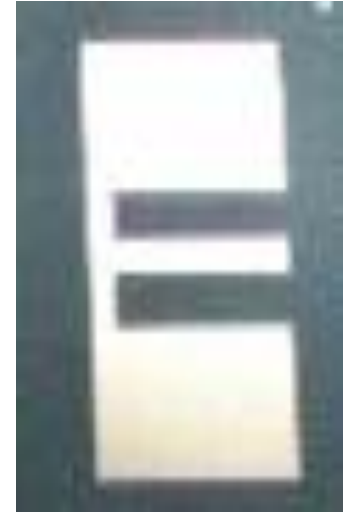

Fig.1. (c) Developed for fabrications.

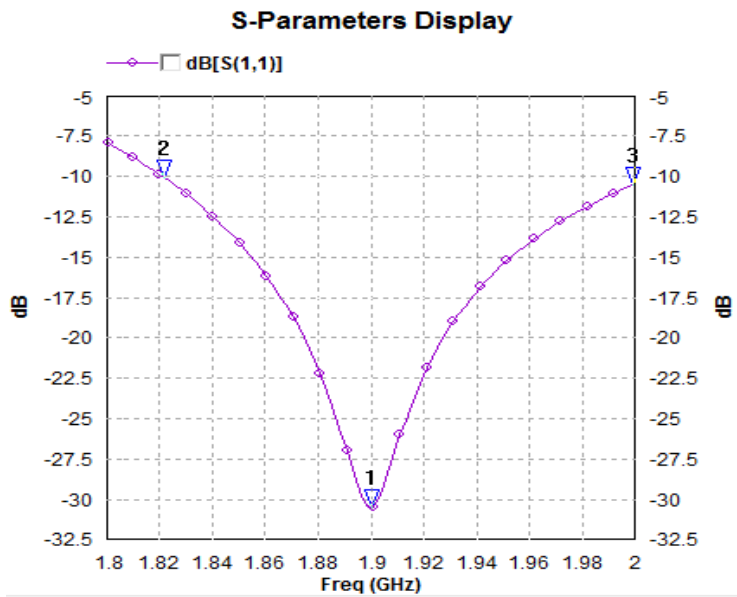

Fig. 2: The return loss S11 parameter. E-shape microstrip patch antenna

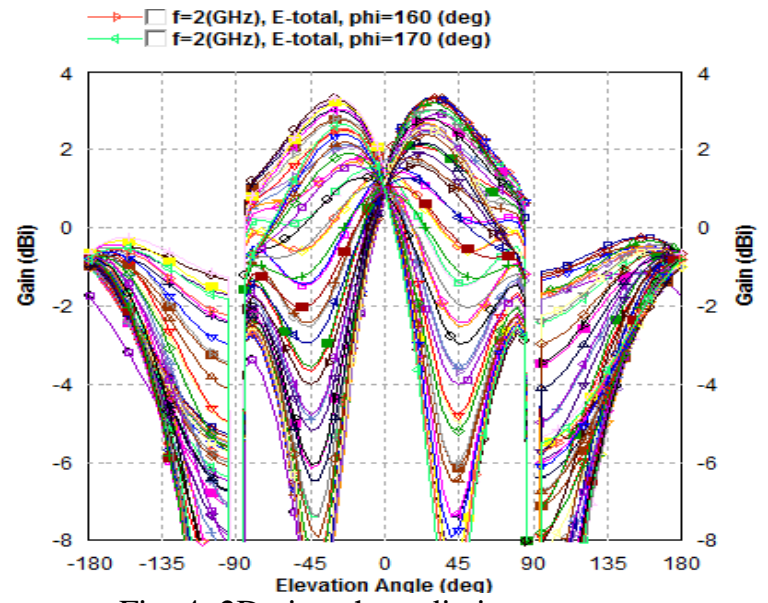

Fig. 4: $2 \mathrm{D}$ view the radiation pattern, at Gain $=3 ; 2 \mathrm{dBi}$ at $\mathrm{f}=1.9 \mathrm{GHz}$;

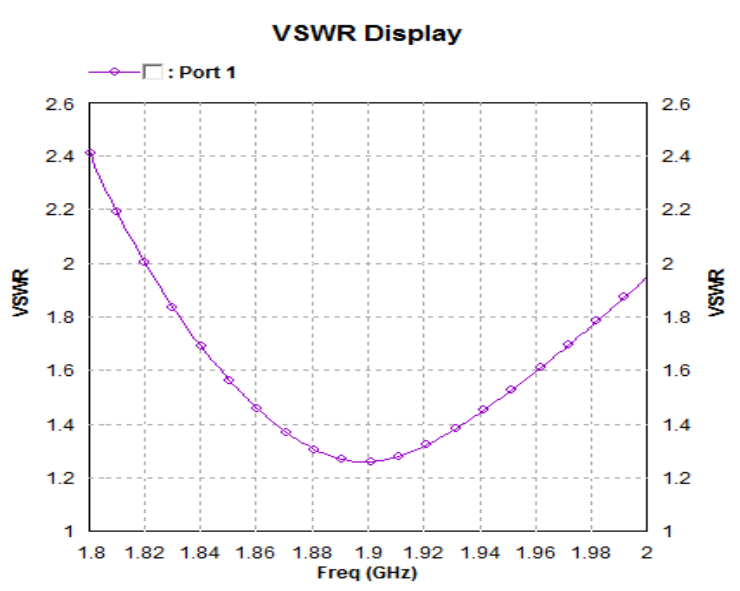

Fig. 3: Simulated VSWR of the proposed patch antenna is 1.25 at $\mathrm{f}=1.9 \mathrm{GHz}$.

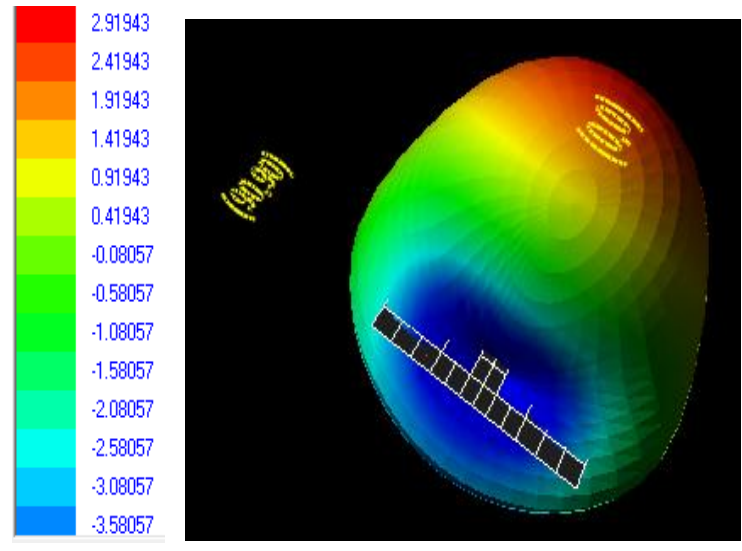

Fig. 5: 3D view of radiation pattern looking along $Z$ axis in the X-Y Plane. 


\begin{tabular}{l}
$-0 \mathrm{~dB}$ \\
$-3 \mathrm{~dB}$ \\
$-6 \mathrm{~dB}$ \\
$-9 \mathrm{~dB}$ \\
$-12 \mathrm{~dB}$ \\
$-15 \mathrm{~dB}$ \\
$-18 \mathrm{~dB}$ \\
$-21 \mathrm{~dB}$ \\
$-24 \mathrm{~dB}$ \\
$-27 \mathrm{~dB}$ \\
$-30 \mathrm{~dB}$ \\
$-33 \mathrm{~dB}$ \\
$-36 \mathrm{~dB}$ \\
$-39 \mathrm{~dB}$ \\
$-42 \mathrm{~dB}$ \\
$-45 \mathrm{~dB}$ \\
\hline
\end{tabular}

Fig..6. Simulated current distributions on the E-shaped patch of antenna at $1.9 \mathrm{GHz}$.

\section{Efficiency Vs. Frequency}

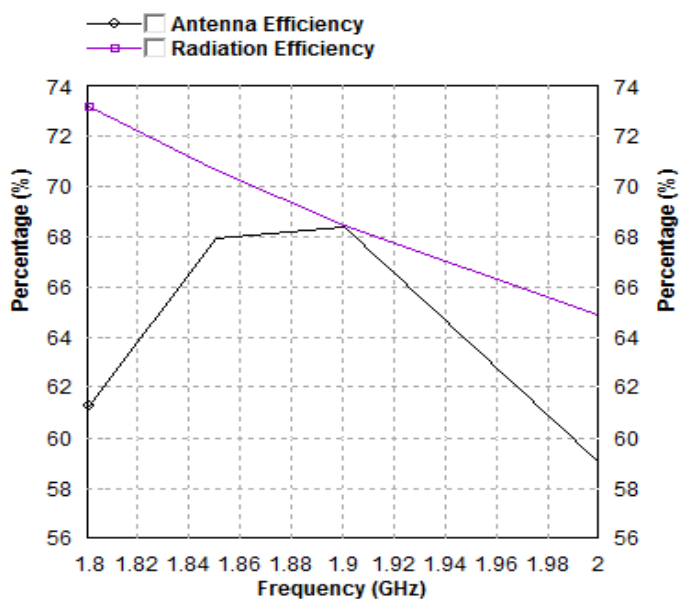

Fig. 7. Simulated the total antenna efficiency and radiation efficiency. 